\title{
EFFECT OF VARYING VOLTAGE ON ELECTRON DENSITY IN OXYGEN HOMOGENEOUS DIELECTRIC BARRIER DISCHARGE UNDER ATMOSPHERIC PRESSURE
}

\author{
Ali Akbar Khan ${ }^{1 a^{*}}$, S L Yap ${ }^{1 b}$, Zaira Zaman Chowdhury ${ }^{2 c}$ \\ ${ }^{1}$ Plasma Technology Research Centre, Department of Physics, Faculty of Science, University of Malaya, 50603, Kuala \\ Lumpur, MALAYSIA. Email: aakhan.um.plasma@gmail.comª; yapsl@um.edu.myb \\ ${ }^{2}$ Nanotechnology and Catalysis Research Centre (NANOCAT), University of Malaya, 50603, Kuala Lumpur, MALAYSIA. \\ Zaira. Email: chowdhury76@gmail.com ${ }^{\mathrm{c}}$ \\ *Corresponding Author: aakhan.um.plasma@gmail.com \\ DOI: https://doi.org/10.22452/mjs.sp2019no3.2
}

\begin{abstract}
The formation of uniform dielectric barrier discharges (DBDs) under atmospheric pressure is a remarkable achievement with the addition of electronegative gasses in closed reactors. This work is the part of dielectric barrier discharge achieved under atmospheric pressure. A uniform glow discharge is produced in capacitive discharge reactor. An alternating voltage source $(0-2.5) \mathrm{kV}$ having frequency of $50 \mathrm{~Hz}$ is applied across the two parallel disc electrodes. A couple of dielectrics (glass) used as a discharge barriers one on each electrode. The oxygen gas injected into the reactor controlled by mass flow controller with flow rate $30 \mathrm{ml} / \mathrm{min}$. The current-voltage waveforms for oxygen discharge achieved, fulfilling the basic conditions of discharge homogeneity. The diagnostic techniques rely on electrical discharge method and power balance method to differentiate discharges and estimate the electron density for different values of applied voltages. A significant relation is found indicating the variation of electron density with applied voltage.
\end{abstract}

Keywords: DBD, I-V waveforms, uniform discharge, power balance method, electron density

\section{INTRODUCTION}

Dielectric barrier discharge is typically produced when a dielectric material is inserted into the gap between the two conductive electrodes. DBDs are known to be produce for one or more dielectrics to sustain glow discharge without switching to arc discharge. The basic features of dielectric include the limitation of transmitted charge and to spread discharge over its surfaces. The addition of dielectric materials also bounds the discharge to produce only by alternating voltage sources. DBDs are distinguished from glow discharge in the sense that electrodes are not in physical contact with the plasma.
The generation and stabilization of dielectric barrier discharge has got much attention in the wake of primacy and its approach to industrial level. Uniform and stable discharges with vacuum reactor has many advantages in the fields of industry, medicine and environment, such as surface modification, deposition, cleaning, removal of pollution and sterilization (Fang et al., 2009; Mahendran \& Alagusundaram, 2015; Rajasekaran et al., 2010; Zhi, Yuchang, \& Hui, 2004). All of the above processes can be enhanced significantly by understanding the basic plasma manifestations and knowing its intrinsic parameters. The dielectric barrier discharge plasma is a synergical process depends upon a number of system parameters like electrodes gap, electrodes geometry, type of gas, 
gas composition, applied voltage, type of dielectric material and source frequency etc. (Kanazawa, Kogoma, Moriwaki, \& Okazaki, 1988; Okazaki, Kogoma, Uehara, \& Kimura, 1993). According to the reported work by several investigators, the homogeneous mode of DBD is sustainable under reduced pressure (Ulrich Kogelschatz, 2003; Massines, SarraBournet, Fanelli, Naudé, \& Gherardi, 2012), While filamentary under atmospheric pressure (Massines et al., 1998). Although under atmospheric pressure the controlling of mean energy of electrons play a key role in approaching a homogeneous discharge. The mean energy of electron can be controlled by varying system parameters like shape of electrodes and type of dielectrics (U Kogelschatz, 2001). According to Kanazawa homogeneous discharge is closely related to the system parameters like geometry of the electrodes, the type of ignited gas and the source frequency. He achieved the homogeneous discharge in $\mathrm{O}_{2} / \mathrm{CF}_{4} / \mathrm{He}$ gasses under atmospheric pressure (Kanazawa et al., 1988; Okazaki et al., 1993; Tepper \& Lindmayer, 2000). H. Ghomi investigated the effect of dielectric barrier and electrodes gap on the formation of homogeneous discharge (Ghomi, Safa, \& Ghasemi, 2011). He used quartz plate and quartz plate plus paper separately as a dielectrics and achieved uniform discharge. $\mathrm{He}$ concluded from the experimental results that shorter electrodes gap, can stabilize the discharge more easily.

Non-thermal plasma with dielectric barrier discharges has many advantages related to their low cost, convenience and simplicity of the operating system (Eliasson \& Kogelschatz, 1988; Ulrich Kogelschatz, Eliasson, \& Egli, 1997). Under atmospheric pressure the use of expensive vacuum machines are no longer use, which justify the significance of DBDs (Di, Zhang, \& Zhang, 2018; Niu et al., 2018). However the stabilization of discharge under atmospheric pressure is still a dilemma of ongoing research. Especially in electronegative gasses like air and oxygen. Because in these gasses the meta-stable species prevent ionization process and induce electron attachments reactions. So, these gasses generally induce filamentary discharges under atmospheric pressure (Nakagawa, Ono, \& Oda, 2018; Shao, Wang, Zhang, \& Yan, 2018).

Electron temperature and electron density are among the fundamental parameters of DBD plasma. Different diagnostic techniques are applied to measure the electron density and electron temperature. The diagnostic methods include optical emission spectroscopy (OES), electric probe, LASER Thomson Scattering and microwave interferometer (Goktas et al., 2007). Among these methods, electric probe and microwave based diagnostic techniques are not reliable under atmospheric pressure owing to the small volume of discharge between the electrodes and short pulse duration of plasma species. Also the reactive nature of oxygen plasma can harm the probe's tip and the recorded data becomes unreliable. Optical emission spectroscopy (OES) is the non-intrusive diagnostic technique which diagnose the plasma parameters like gas temperature, electron density $\left(\mathrm{n}_{\mathrm{e}}\right)$ and electron velocity distribution function (EVDF). In OES technique the emitted photons are recorded in the form of intensity vs wavelength spectra. Line intensity ratio method is the type of OES technique utilized to calculate electron temperature and electron density of the reactive plasma (Balcon, Aanesland, \& Boswell, 2007; Dong, Qi, Zhao, \& Li, 2008). Power balance method is the other diagnostic technique to find the electron density in DBD plasma (Shrestha, Tyata, \& Subedi, 2013). According to the power balance method the total power delivered to the plasma species is assumed to be balanced by the applied power. 
In this study the parallel plate electrodes assembly is used to produce homogeneous discharge in oxygen gas under atmospheric pressure. The discharge initiated with frequency of $50 \mathrm{~Hz}$ alternating voltage source. The homogenous discharge generated and spreads over the entire surfaces of dielectrics. The current-voltage waveforms recorded through digital oscilloscope (Tektronix TDS 2024B), showing full cycle of discharge current per half cycle of the applied voltage. Electron density is a significant parameter of stable discharge can be estimated using power balance method.

\section{EXPERIMENTAL SET-UP}

The dielectric barrier discharge schematic diagram is shown in figure. 1. The dielectric barrier discharge is obtained using specially designed reactor having fixed area of electrodes. The circular brass electrodes are put together in plane parallel configuration having diameter of $80 \mathrm{~mm}$ and thickness of $6 \mathrm{~mm}$ each. Each electrode is covered by a glass dielectric. The glass plate having diameter of $100 \mathrm{~mm}$ with thickness of $3 \mathrm{~mm}$ each. The electrodes assembly is fixed in triangular insulating stand to make it electrically isolate from reactor. The electrodes assembly is enclosed by a stainless steel reactor having internal diameter of $320 \mathrm{~mm}(32 \mathrm{~cm})$ and height of $160 \mathrm{~mm}(16 \mathrm{~cm})$. The discharge gap is set to $4 \mathrm{~mm}$ between the electrodes. For homogeneous discharge, oxygen is supplied to the reactor with gas flow rate of $30 \mathrm{ml} / \mathrm{min}$ controlled by mass flow controller (Model GFC2104 via Flow Range 0 100 mL/min). An adjustable high voltage power source having amplitude from 0 to $2.5 \mathrm{kV}$ and frequency of $50 \mathrm{~Hz}$ is connected to the upper electrode. The applied voltage between the electrodes is measured via a high voltage probe (Tektronix P6015A via $1000 \times 3.0 \mathrm{pF}, 100 \mathrm{M} \Omega$ ). The discharge current and transported charges can be measured by placing a resistor of $10 \mathrm{k} \Omega$ and a capacitor $(0.47 \mu \mathrm{F})$ between the ground and bottom electrode respectively. The voltage and current waveforms are recorded in the personal computer, coupled with digital Oscilloscope (Tektronix TDS 2024B via 200MHz, 2GS/s). The applied frequency is fixed to $50 \mathrm{~Hz}$ for all measurements, while applied voltage to the electrodes will be varying to study its effect on the electron density.

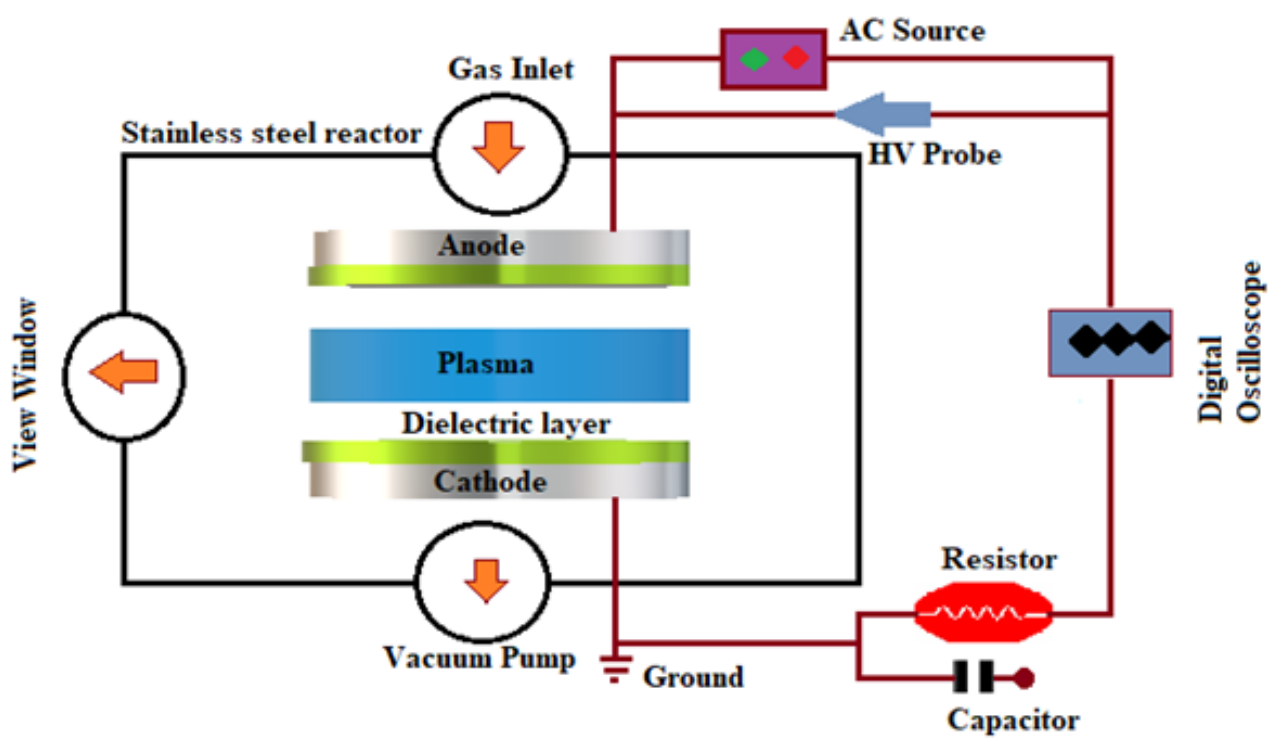

Figure 1. Schematic diagram of experimental set-up for DBD generation. 


\section{POWER BALANCE METHOD}

Power balance characterization technique described by R. Shrestha determines electron density of DBD plasma operating at homogeneous mode (Shrestha et al., 2013; Subedi, Shrestha, Tyata, \& Wong, 2017). According to this method the energy lost by each electron and ion within plasma can be written as;

$$
E_{\text {lost }}=K . E_{\text {ions }}+K \cdot E_{\text {electrons }}+K \cdot E_{\text {collisional }}
$$

Here $K . E_{\text {ions }}$ is the kinetic energy gained by ions falling down to plasma sheath wall $\left(E_{\text {ions }}=V_{p l}+\right.$ $\left.1 / 2 T_{e}\right)$, where $V_{p l}$ is the plasma potential. $K . E_{\text {electrons }}$ be the mean kinetic energy lost per electron to the sheath wall having Maxwellian electron energy distribution $\left(E_{\text {electrons }} \approx 2 \mathrm{KT}_{e}\right)$. While K. $E_{\text {collisional }}$ is the collisional energy

$$
P_{a b s}=\mathrm{IV}
$$

Here "I" represents the discharge current and is given by;

$$
\mathrm{I}=2 \operatorname{Aen}_{e} V_{b}
$$

Here " $\mathrm{A}$ " is the area of the electrodes, " $\mathrm{e}$ " is charge on electron, " $n_{e}$ " is the electron density and" $v_{b}$ " is the ion velocity entering into the sheath called Bohm velocity $\left(V_{b}=\left(\sqrt{e T_{e} / m_{i}}\right)\right.$. loss of electron-ion pairs produced (Guðmundsson). $T_{e}$ is the electron temperature and its mean value is $3.6 \mathrm{eV}$ for oxygen DBD at atmospheric pressure (Hassouba, 2008).

Then the input power supplied and absorbed by the gas plasma is;

$$
\mathrm{V}=E_{\text {lost }} \mathrm{d}
$$

Here "E" is the electric potential energy or kinetic energy of electrons between the electrodes and " $\mathrm{d}$ " is the separation between
Where $m_{i}$ is the mass of ion and $T_{e}$ is the electron temperature.

And "V" is the potential difference between the two electrodes is calculated from potential gradient equation i.e.

the electrodes. "E" will be lost in the case of kinetic energy and will be gain in the case of potential energy for electrons. 
Inserting values in equation (1),

$$
P_{\_a b s}=2 A e n_{-} \text {e } V_{-} b E_{-} \text {lost } \mathrm{d}
$$

Then

$$
\mathrm{n}_{-} \mathrm{e}=\mathrm{P}_{-} \mathrm{abs} / 2 \mathrm{Ae} \mathrm{v}_{-} \mathrm{b} \mathrm{E}_{-} \text {lost } \mathrm{d}
$$

Equation (6) will calculate the relative electron density for homogeneous mode of DBD. Here are the values mentioned in Table. 1.

Table 1. List of system/plasma parameters and their calculated values.

\begin{tabular}{ccc}
\hline S.N & System/Plasma parameters & Calculated values \\
\hline 1 & Electrodes gap $(\mathrm{d})$ & $10 \mathrm{~mm}\left(10^{-2} \mathrm{~m}\right)$ \\
2 & Area of each electrode $(\mathrm{A})$ & $50.72 \times 10^{-4} \mathrm{~m}^{2}$ \\
3 & Bohm velocity $\left(V_{b}\right)$ & $4.64 \times 10^{3} \mathrm{~m} / \mathrm{s}$ \\
4 & Energy loss $\left(E_{\text {lost }}\right)$ & $80.18 \mathrm{eV}$ \\
5 & Charge on electron $(\mathrm{e})$ & $1.6 \times 10^{-19} \mathrm{C}$ \\
6 & Power absorbed $\left(P_{a b s}\right)$ & $\mathrm{IV}$ \\
\hline
\end{tabular}

\section{RESULTS AND DISCUSSIONS}

The homogeneous dielectric barrier in $4 \mathrm{~mm}$ discharge gap obtained and corresponding oscillogrms of the applied voltage and discharge current are shown in Figures. 2-5. All measurements performed under atmospheric pressure. For homogeneous dielectric barrier discharge no filament is observed and discharge is radially symmetric between the electrodes covering the whole surfaces uniformly. The homogeneous discharge is relatively more luminous near the cathode surface. Also having single pulse of discharge current per half cycle of the applied voltage (All waveforms of figures. 2-5). 


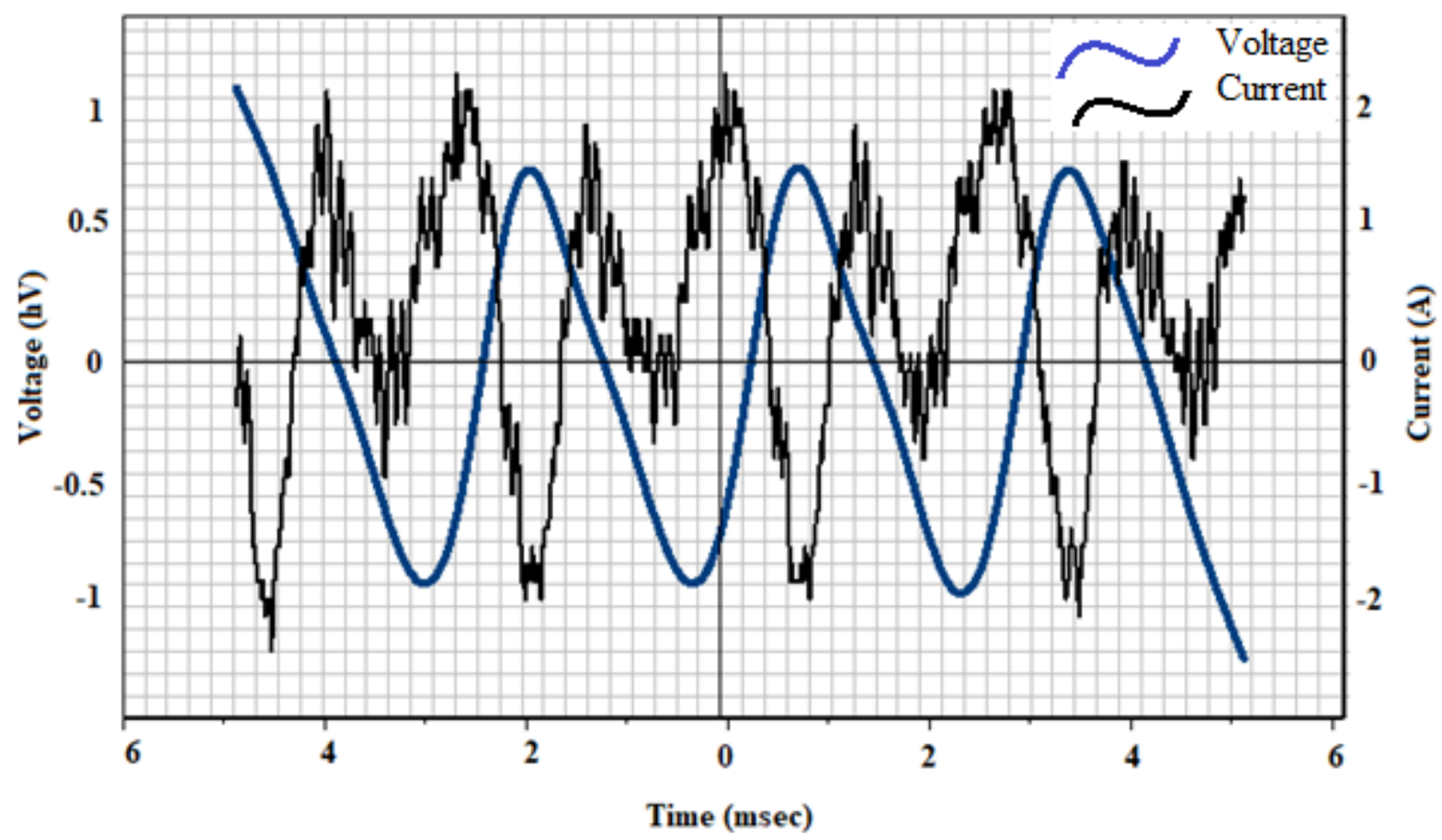

Figure 2. Current-voltage waveforms of the homogeneous discharge under applied voltage of $100 \mathrm{~V}$.

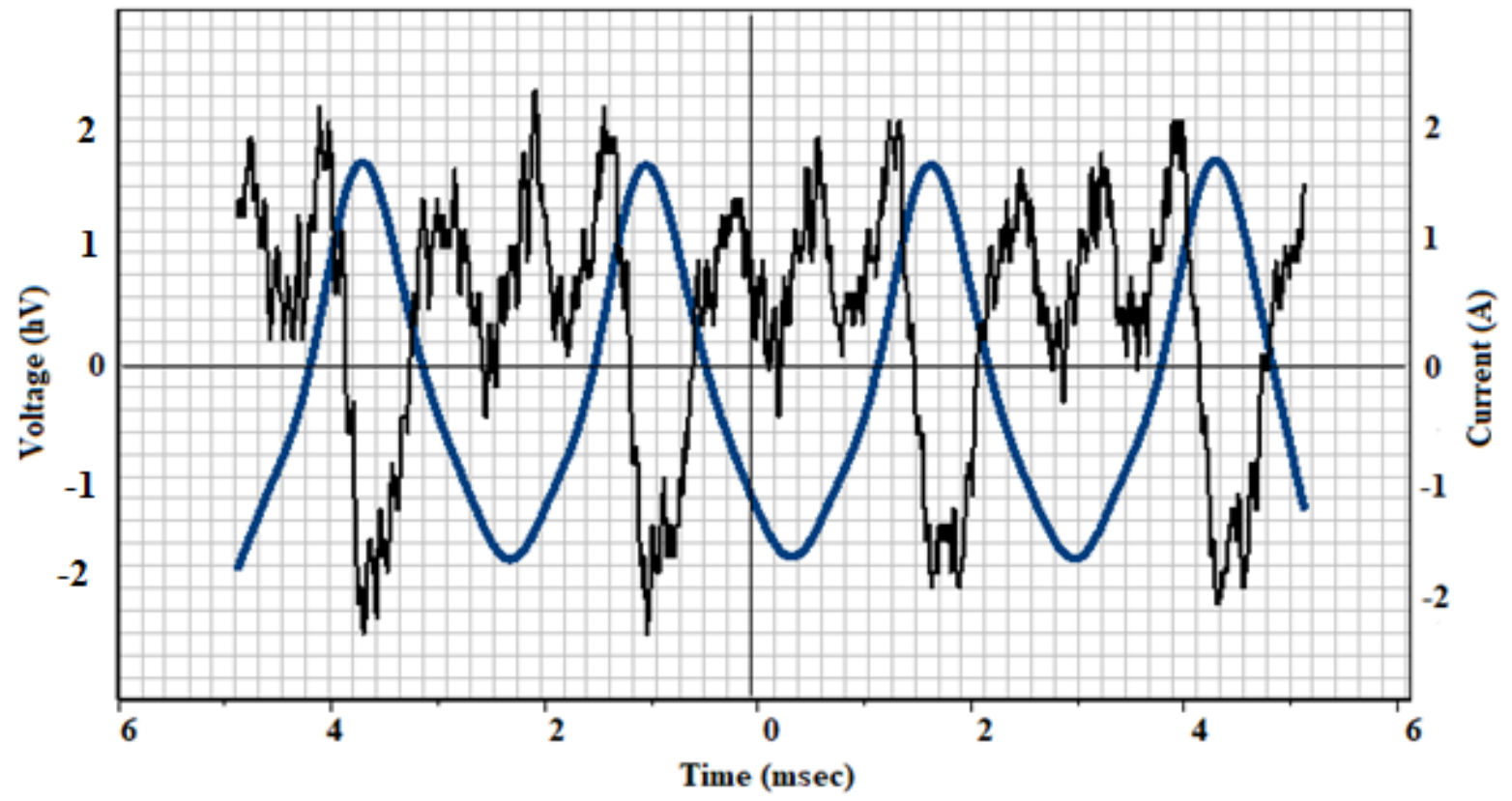

Figure 3. Current-voltage waveforms of the homogeneous discharge under applied voltage of $200 \mathrm{~V}$. 


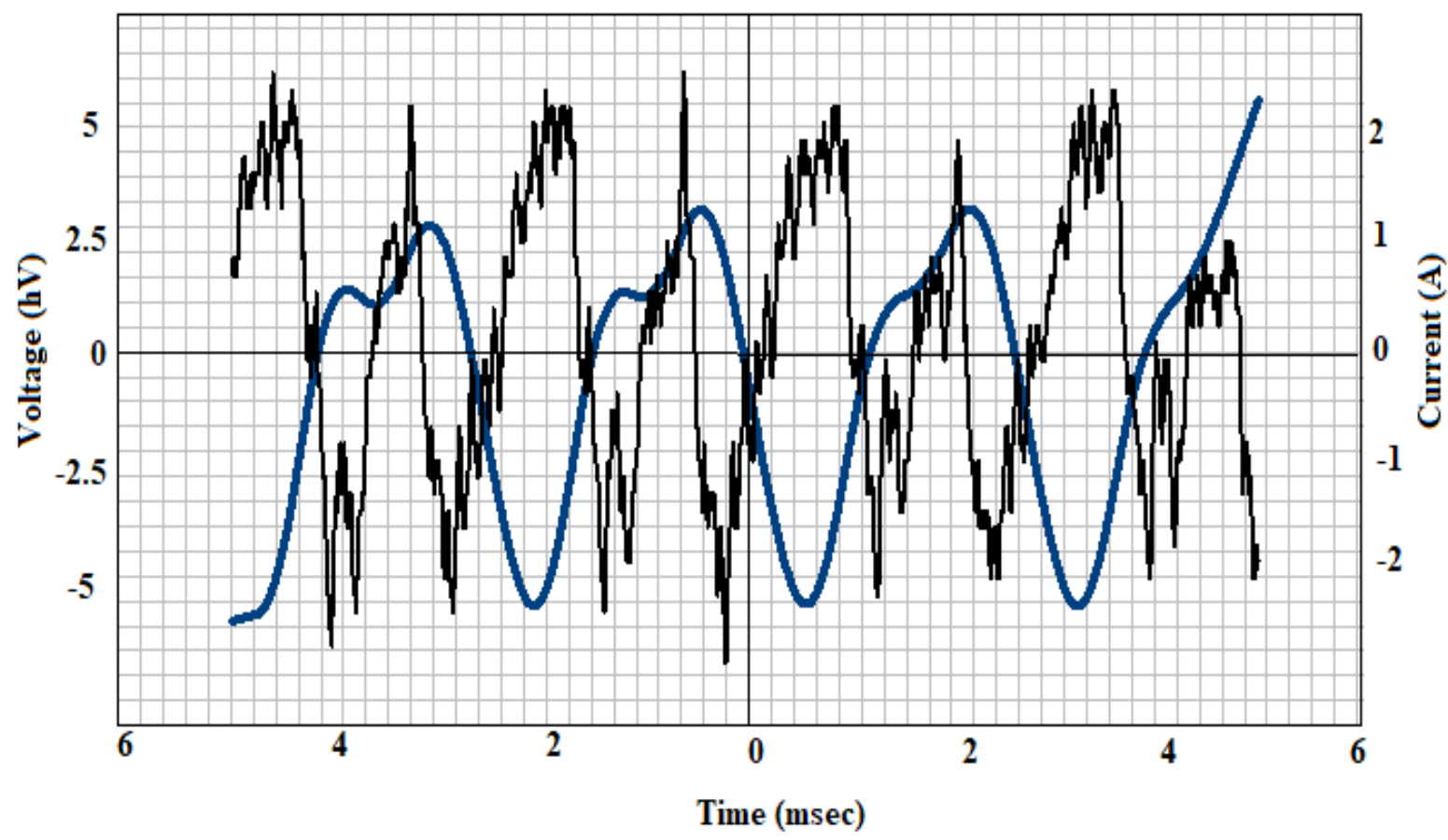

Figure 4. Current-voltage waveforms of the homogeneous discharge under applied voltage of 500V.

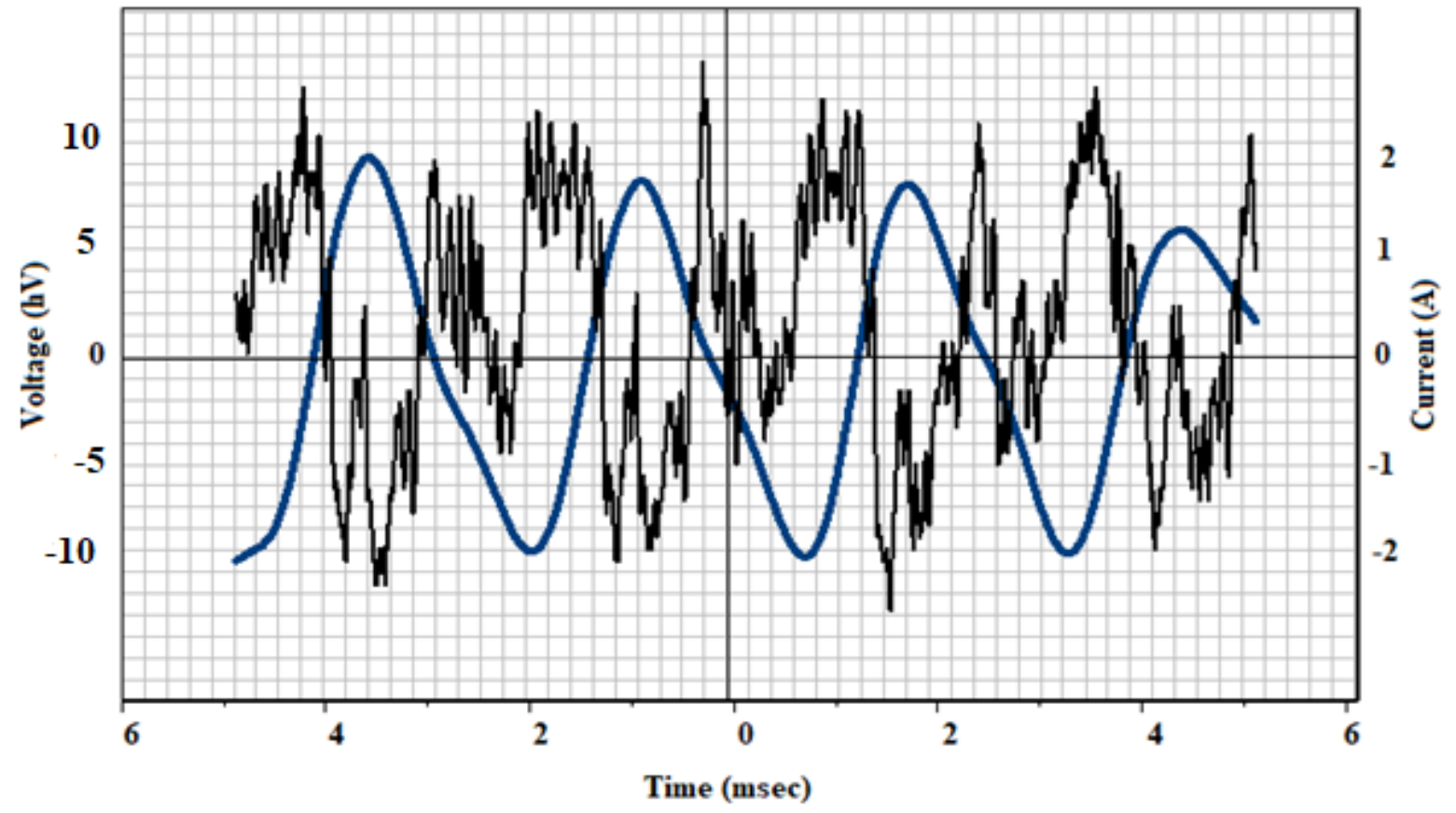

Figure 5. Current-voltage waveforms of the homogeneous discharge under applied voltage of $1 \mathrm{kV}$.

The constant periods of both current and voltage waveforms should match each other for a perfect homogeneity. Since the polarity of AC voltage changes every half cycle, two luminous circles can be seen near the electrodes. The voltage current waveforms display sine wave, 
representing the nature of discharge similar to glow discharge under reduced pressure. According to the voltage and current waveforms:

$$
\begin{aligned}
& V=V_{0} \sin \omega t \\
& I=I_{0} \sin \left(\omega t+90^{\circ}\right)
\end{aligned}
$$

It is obvious from equation (8) that discharge current leads voltage by $90^{\circ}$. In other words the discharge current is cosine with sinusoidal applied voltage. This shows the capacitive nature of DBD system. Sinusoidal voltage is an important parameter of discharge can change the electron density significantly. When the voltage is increased, the charge species will gain more and more energy from the applied electric field and its kinetic energy will increase. The increase in kinetic energy of the plasma species will change the collisional mode from elastic to inelastic. So, secondary electron emission process starts and will further enhance with the increase of applied voltage. The related $\mathrm{I}-\mathrm{V}$ waveforms (2-5) show the confirmation of discharge homogeneity in oxygen discharge using different voltages under atmospheric pressure. The values of applied voltages and corresponding discharge currents are taken from waveforms (2-5) to estimate the electron density in each case using Eq. (6). The list of obtained values for electron densities with corresponding applied voltages are shown in Table 2.

Table 2. List of calculated values of electron density across each value of applied voltage.

\begin{tabular}{ccc}
\hline S.N & Applied Voltage $(\mathrm{V})$ & $\begin{array}{c}\text { Electron density } \\
n_{e} \times 10^{20}\left(\mathrm{~m}^{-3}\right)\end{array}$ \\
\hline 1 & 100 & 0.3 \\
3 & 200 & 0.6 \\
4 & 500 & 1.6 \\
\hline
\end{tabular}

The graph between the applied voltages and electron densities are plotted below. The voltage vs density graph shows that both quantities are directly related to each other. The graph depicts linear behavior for electron density as the applied voltage goes up. 


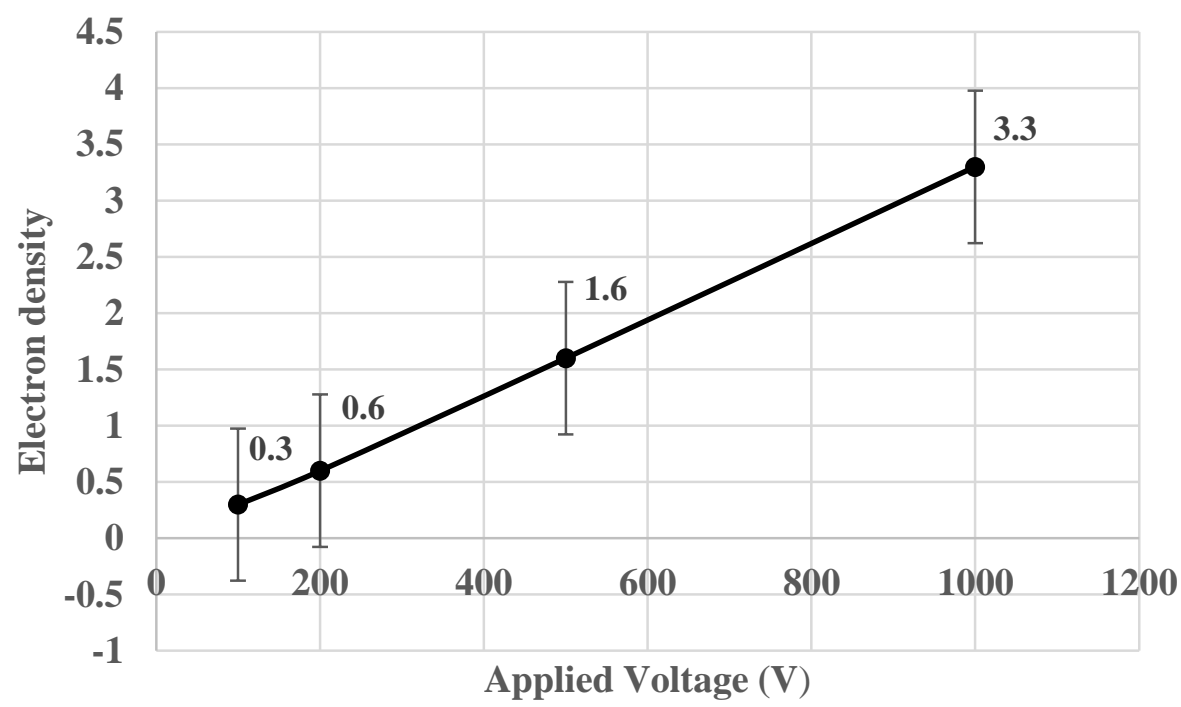

Figure 6. Graphical representation of variation between applied voltage and electron density.

\section{CONCLUSIONS}

It is demonstrated here that oxygen homogeneous discharge is produced using parallel plate disc electrodes system. Two glass plates are used as a dielectrics with $4 \mathrm{~mm}$ electrodes gap. An alternating high power source $(50 \mathrm{~Hz})$ employed to attain discharge. The discharge homogeneity conditions are verified by achieving current-voltage waveforms with the same periodicity. Electron density in homogenous discharge is highlighted here. The diagnostic technique relies on power balance method to estimate the value of electron density under atmospheric pressure. The results conclude that electron density and applied voltage are correlated by an important relation. The relation depicts that electron density increases with the increase of potential difference between the electrodes.

\section{ACKNOWLEDGMENTS}

The authors are thankful for the funding provided from the Grant No. RP044C-17AET and RP044D-17AET from the University of Malaya, Malaysia.

\section{REFERENCES}

Balcon, N., Aanesland, A., \& Boswell, R. (2007). Pulsed RF discharges, glow and filamentary mode at atmospheric pressure in argon. Plasma Sources Science and Technology, 16(2), 217.

Di, L., Zhang, J., \& Zhang, X. (2018). A review on the recent progress, challenges, and perspectives of atmospheric-pressure cold plasma for preparation of supported metal catalysts. Plasma Processes and Polymers, 15(5), 1700234.

Dong, L., Qi, Y., Zhao, Z., \& Li, Y. (2008). Electron density of an individual microdischarge channel in patterns in a dielectric barrier discharge at atmospheric pressure. Plasma Sources Science and Technology, 17(1), 015015.

Eliasson, B., \& Kogelschatz, U. (1988). UV excimer radiation from dielectric-barrier 
discharges. Applied Physics B, 46(4), 299-303.

Fang, Z., Xie, X., Li, J., Yang, H., Qiu, Y., \& Kuffel, E. (2009). Comparison of surface modification of polypropylene film by filamentary DBD at atmospheric pressure and homogeneous DBD at medium pressure in air. Journal of Physics D: Applied Physics, 42(8), 085204.

Ghomi, H., Safa, N. N., \& Ghasemi, S. (2011). Investigation on a DBD plasma reactor. IEEE Transactions on plasma science, 39(11), 2104-2105.

Goktas, H., Demir, A., Kacar, E., Hegazy, H., Turan, R., Oke, G., \& Seyhan, A. (2007). Spectroscopic measurements of electron temperature and electron density in electron beam plasma generator based on collisional radiative model. Spectroscopy letters, 40(1), 183-192.

Guðmundsson, J. T. Notes on the electron excitation rate coefficients for argon and oxygen discharge: Raunvísindastofnun Háskólans.

Hassouba, M. A. (2008). Determination of the electrons temperature in a dielectric barrier discharge. Plasma Devices and Operations, 16(2), 81-88.

Kanazawa, S., Kogoma, M., Moriwaki, T., \& Okazaki, S. (1988). Stable glow plasma at atmospheric pressure. Journal of Physics D: Applied Physics, 21(5), 838.

Kogelschatz, U. (2001). Filamentary and diffuse barrier discharges. Paper presented at the 2001 APP Spring Meeting Bad Honnef.

Kogelschatz, U. (2003). Dielectric-barrier discharges: their history, discharge physics, and industrial applications. Plasma chemistry and plasma processing, 23(1), 1-46.
Kogelschatz, U., Eliasson, B., \& Egli, W. (1997). Dielectric-barrier discharges. Principle and applications. Le Journal de Physique IV, 7(C4), C4-47-C44-66.

Mahendran, R., \& Alagusundaram, K. (2015). Uniform discharge characteristics of non-thermal plasma for superficial decontamination of bread slices. International Journal of Agricultural Science and Research (IJASR), 5(2), 209-212.

Massines, F., Rabehi, A., Decomps, P., Gadri, R. B., Ségur, P., \& Mayoux, C. (1998). Experimental and theoretical study of a glow discharge at atmospheric pressure controlled by dielectric barrier. Journal of Applied Physics, 83(6), 2950-2957.

Massines, F., Sarra-Bournet, C., Fanelli, F., Naudé, N., \& Gherardi, N. (2012). Atmospheric pressure low temperature direct plasma technology: status and challenges for thin film deposition. Plasma Processes and Polymers, 9(1112), 1041-1073.

Nakagawa, Y., Ono, R., \& Oda, T. (2018). Effect of discharge polarity on $\mathrm{OH}$ density and temperature in coaxial-cylinder barrier discharge under atmospheric pressure humid air. Japanese journal of applied physics, 57(9), 096103.

Niu, C.-B., Qin, S., Zhang, X., Zhao, H.-X., Liu, X., Mu, H.-B., \& Zhang, G.-J. (2018). Discharge characteristics of argon atmosphere dielectric barrier with different pd values. Paper presented at the 2018 12th International Conference on the Properties and Applications of Dielectric Materials (ICPADM).

Okazaki, S., Kogoma, M., Uehara, M., \& Kimura, Y. (1993). Appearance of stable glow discharge in air, argon, oxygen and nitrogen at atmospheric pressure using a 
$50 \mathrm{~Hz}$ source. Journal of Physics D: Applied Physics, 26(5), 889.

Rajasekaran, P., Mertmann, P., Bibinov, N., Wandke, D., Viöl, W., \& Awakowicz, P. (2010). Filamentary and homogeneous modes of dielectric barrier discharge (DBD) in air: investigation through plasma characterization and simulation of surface irradiation. Plasma Processes and Polymers, 7(8), 665-675.

Shao, T., Wang, R., Zhang, C., \& Yan, P. (2018). Atmospheric-pressure pulsed discharges and plasmas: mechanism, characteristics and applications. High voltage, 3(1), 1420.

Shrestha, R., Tyata, R., \& Subedi, D. (2013). Effect of applied voltage in electron density of homogeneous dielectric barrier discharge at atmospherice pressure. Himalayan Physics, 4, 10-13.

Subedi, D. P., Shrestha, R., Tyata, R. B., \& Wong, C. S. (2017). Generation and diagnostics of atmospheric pressure dielectric barrier discharge in argon/air. Indian Journal of Pure \& Applied Physics (IJPAP), 55(2), 155-162.

Tepper, J., \& Lindmayer, M. (2000). Investigations on two different kinds of homogeneous barrier discharges at atmospheric pressure. Paper presented at the Proc. of Int. Symp. on High Pressure, Low Temperature Plasma Chemistry.

Zhi, F., Yuchang, Q., \& Hui, W. (2004). Surface treatment of polyethylene terephthalate film using atmospheric pressure glow discharge in air. Plasma Science and Technology, 6(6), 2576. 